\author{
J. Labanowski ${ }^{1}$, S. Topolska ${ }^{2}$, J. Ć Tiek $^{3}$, \\ ${ }^{1}$ Department of Materials Technology and Welding, Gdansk University of Technology, \\ 11/12 Narutowicza, 80-952 Gdansk, Poland \\ ${ }^{2}$ Institute of Engineering Materials and Biomaterials, Silesian University of Technology, \\ 18A Konarskiego, 44-100 Gliwice, Poland \\ ${ }^{3}$ Department of Materials Science and Engineering, Gdansk University of Technology, \\ 11/12 Narutowicza, 80-952 Gdansk, Poland
}

\title{
ASSESSMENT OF EVAPORATOR TUBES CORROSION IN LOW-EMISSION STEAM BOILERS
}

\begin{abstract}
Degradation examinations of outer surface of low-emission steam boiler evaporator tubes are presented in the paper. Metallographic evaluation of scale morphology, its micro sites chemical composition analysis and distribution of elements on cross sections have been performed. Water-wall tubes were exposed in steam boiler for up to two years period. Common tubes made of $16 \mathrm{Mo} 3$ steel suffered sulfide and molten salts corrosions. Thermal sprayed tubes with the single layer of $70 \% \mathrm{Ni} 30 \% \mathrm{Cr}$ alloy show better corrosion resistance, but become also susceptible to sulfide corrosion due to presence of internal voids and cracks. Double layer $\mathrm{Al}_{2} \mathrm{O}_{3} / \mathrm{Ni}-30 \mathrm{Cr}$ coatings withstand corrosion attack for more than one year operation, then failed due to internal heterogeneity and cracks generation.
\end{abstract}

Key words: low-emission steam boiler, evaporator tubes, sulfide corrosion, thermal sprayed coatings

\section{INTRODUCTION}

Coal fired boilers are serious source of environmental pollution. When ashes and solid particles from the flue gases can be eliminated on electro filters, nitride oxides $\left(\mathrm{NO}_{\mathrm{x}}\right)$ can be only reduced through modification of combustion process. These modifications aim to limitation of air excess at the burners exhaust area, which reduce production of high-temperature nitride oxides. Application of low-emission combustion process results in increase corrosion of water wall tubes. The major causes of tube corrosion are: the reducing (substiochiometric) gas environment causing sulfide corrosion and/or molten salt attack [1,2].

Corrosion of the water wall tubes in low-emission steam boilers may be a result of reaction of steel tube surface with the aggressive substiochiometric environment contains sulfur. In oxidizing atmospheres sulphur reacts with oxygen to form $\mathrm{SO}_{2}$ and $\mathrm{SO}_{3}$. These oxygen-rich atmospheres are often much less corrosive than reducing atmospheres, where the sulphur is found in the form of $\mathrm{H}_{2} \mathrm{~S}$. In reducing conditions iron 
sulfide is the expected corrosion product on iron rather than the iron oxides $\left(\mathrm{Fe}_{3} \mathrm{O}_{4}\right.$, $\mathrm{Fe}_{2} \mathrm{O}_{3}$ ). That sulfide scales allow higher rates of transport of iron cations than oxides do, so they are less protective [1,2]. Reducing conditions can also lower melting temperature of any deposited slag. It leads to local disruption of the oxide film on the wall tubes and accelerated oxidation or to oxidation-sulfidation. The role of chlorine is not well known so far. The presence of this element in reducing combustion atmosphere is reported to enhance corrosion rate. Chlorine probably reacts with oxide scales making them brittle and causing blistering and cracking.

Prevention of waterwall tubes corrosion can be achieved by changing in operation procedures and replacement of tube materials. The first mentioned action is limited to accurate burners adjustment or introduce a flow of additional air along the walls and create air curtain between reducing environment and tubes surface. These efforts often are insufficient. The replacement of more corrosion resistant material on $\mathrm{Cr}$ rich steel or $\mathrm{Cr}-\mathrm{Ni}$ steel is possible but other problems appear connected with high costs of installation and low heat transfer coefficients of such materials. Chromium, aluminum and silicon are beneficial alloying elements for sulfidation resistant steels. Chromium and silicon are good oxide formers even in reducing combustion atmospheres. Iron and nickel in such environment create mainly sulfides. Unalloyed nickel is corroding rapidly in sulfidizing atmosphere above $635^{\circ} \mathrm{C}$, however nickel base alloys can be used above this temperature [3]. Increased corrosion resistance can also be achieved by enriching the tubes surface with chromium and aluminium or performing protective coatings. Coated boiler tubes can be obtained by means of coextrusion, weld overlaying, diffusion processes, thermal spraying and laser cladding [3-5]. The most spread technology is thermal spraying. This method has been used to apply high $\mathrm{Cr}$, high $\mathrm{Al}$ or $\mathrm{Cr}-\mathrm{Ni}$ coatings on water-wall tubes. Good resistances of such coatings in reduction environment were proved in laboratory tests. In real boiler chamber combustion conditions are not stable and can alternate in dependence on coal quality, burner's adjustments, and air flow.

The objective of this study is to compare the corrosion resistance of water-wall tubes with and without thermal sprayed coatings exposed to substiochiometric environment contains sulfur in low $\mathrm{NO}_{\mathrm{x}}$ emission boiler.

\section{EXPERIMENTAL PROCEDURES}

Examinations were conducted on several segments of $\varnothing 57 \times 5.0 \mathrm{~mm}$ evaporator tubes made of $16 \mathrm{Mo} 3$ steel grade. Segments were taken from level of 10 meters from the chamber bottom of low-emission boiler. The highest row of burners was situated on the level 14 meters. The operation temperature on tube surface was estimated at $450^{\circ} \mathrm{C}$. Inspections were made on tubes segments taken from the water-wall after one year and two years of operation.

The first set of samples was taken from uncoated tubes. Second set of samples consist of tubes with thermal sprayed single layer of nickel base alloy Ni70Cr30, and third set consist of thermal sprayed tubes with double layer, Ni70Cr30 alloy and ceramic $\mathrm{Al}_{2} \mathrm{O}_{3}$ layer.

The appearance of cross section of uncoated tube after one year exploitation is shown in Fig.1. Thickness of tube wall was measured at the points indicated in Fig. 1. 
The reduction in wall thickness was not uniform on tube perimeter. The front side of the tube facing the combustion radiant heat suffered the worst metal wastage and reaches $68 \%$ of its nominal value. Reductions in wall thickness from insulation side of tubes were not recorded.

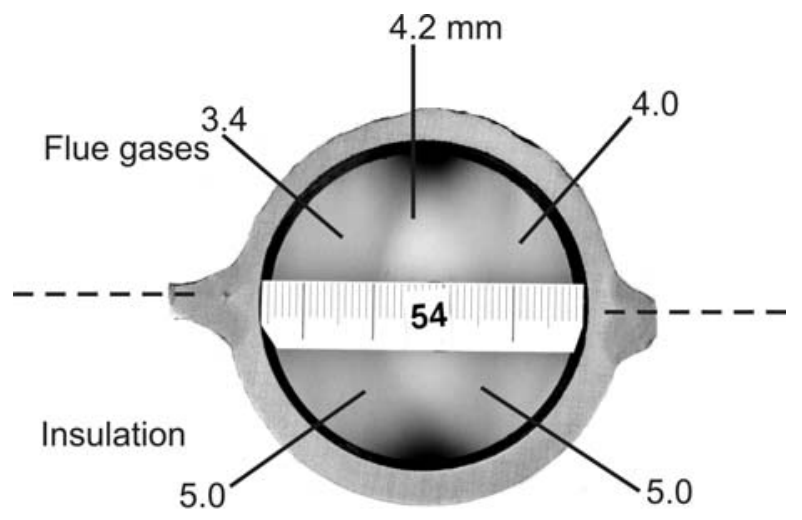

Fig. 1. Cross section of $\varnothing 57 \times 5.0 \mathrm{~mm}$ evaporator tube after one year exploitation in low-emission boiler

Samples with corrosion deposits were taken from each segment and immersed in Woods alloy to prepare metallographic samples. The spot microanalyses of chemical composition at selected points on tubes cross sections were performed. Examinations were conducted with the use of Philips XL30 scanning electron microscope (SEM) equipped with EDS analyzer. Evaluations of chemical compounds existed in deposited layer were performed with the use of X-ray diffraction analysis. Deposits were scratched from the tube surface, then grinded and pressed.

Investigations show that both mechanisms of corrosion (sulfide corrosion and molten salts corrosion) took place on uncoated tubes. Chemical analysis indicated presence of alkaline metals $(\mathrm{K}, \mathrm{Na}, \mathrm{Mg}, \mathrm{Ca})$ and iron sulfides $\left(\mathrm{FeS}, \mathrm{FeS}_{2}\right)$ in the scales. The morphology of scales consisted of two layers. External, which is porous and weakly connected with the tube surface, and internal, which is dense and adherent to the base metal (Fig. 2 and 3). In these two layers the bands rich in sulphur were detected. Concentration of sulphur in these bands reached $22 \mathrm{wt} . \%$. Outer layers consisted of iron, oxygen, sulphur, silicon, aluminium and alkaline metals. Inner layer consisted mainly of iron oxides and iron sulfides. The traces of chlorine were also detected mainly at the interface of inner layer and base material.

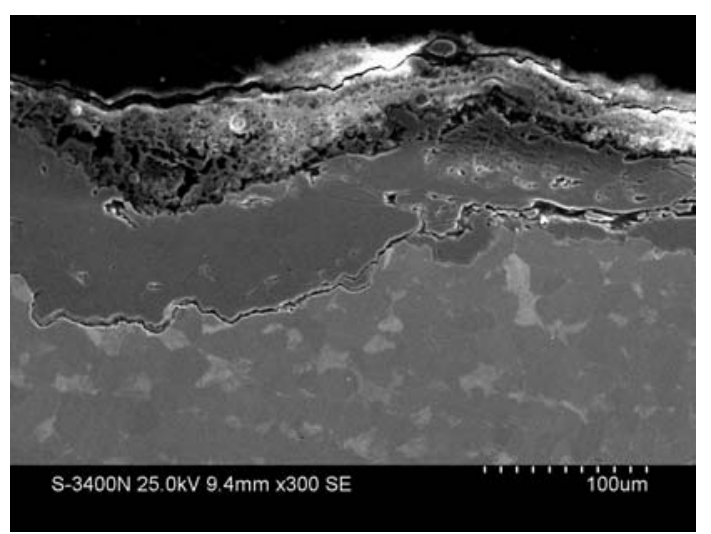

Fig. 2. Cross section of $\varnothing 57 \times 5.0 \mathrm{~mm}$ evaporator tube after one year exploitation. Deposits on the fireside of the tube 
a)

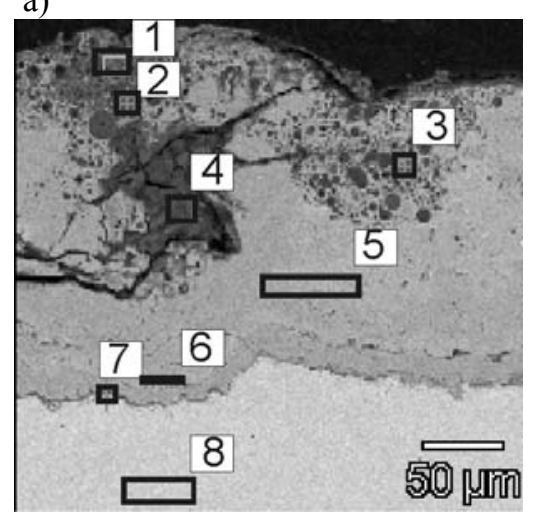

b)

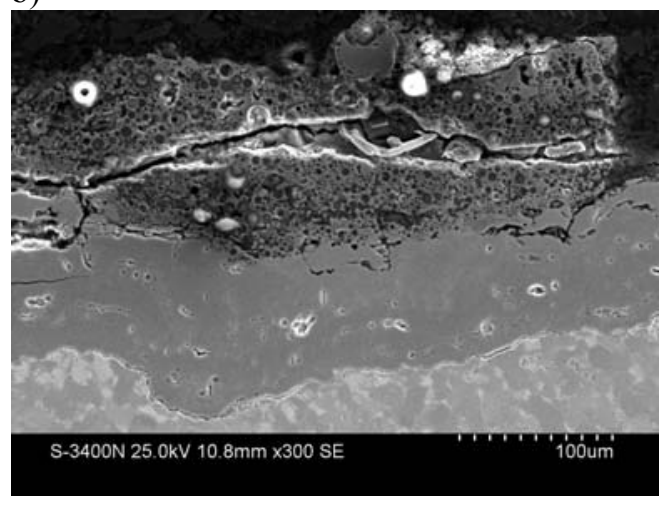

Fig. 3. Cross section of $\varnothing 57 \times 5.0 \mathrm{~mm}$ evaporator tube after one year exploitation; a) places for chemical analysis (EDS), b) general view

Table 1. Chemical analysis at the points indicated in Fig. 3a (wt.\%)

\begin{tabular}{|l|c|c|c|c|c|c|c|c|}
\hline & $\mathrm{Na}$ & $\mathrm{Mg}$ & $\mathrm{Al}$ & $\mathrm{Si}$ & $\mathrm{S}$ & $\mathrm{K}$ & $\mathrm{Ca}$ & $\mathrm{Fe}$ \\
\hline pt1 & & 0.63 & 20.88 & 28.86 & & 1.95 & 0.84 & 46.06 \\
\hline pt2 & & 2.16 & 23.27 & 35.04 & & 4.68 & & 33.77 \\
\hline pt3 & 1.20 & 0.44 & 20.11 & 24.65 & 7.88 & 1.88 & & 43.84 \\
\hline pt4 & 2.24 & & 1.88 & 32.16 & 2.79 & & & 60.93 \\
\hline pt5 & & & & & 14.55 & & & 85.45 \\
\hline pt6 & & & & & 21.76 & & & 77.61 \\
\hline pt7 & & & & 0.56 & 4.68 & & & 94.76 \\
\hline pt8 & & & & 0.43 & & & & 98.91 \\
\hline
\end{tabular}

The tube surface with arc sprayed single layer of $70 \% \mathrm{Ni}$ and $30 \% \mathrm{Cr}$ alloy after one year operation is shown in fig 4 and 5. The thickness of this layer varied from 300 to $450 \mu \mathrm{m}$. Bonding with base material was rather weak because of evidence of many voids and porous structure at material-coating interface.

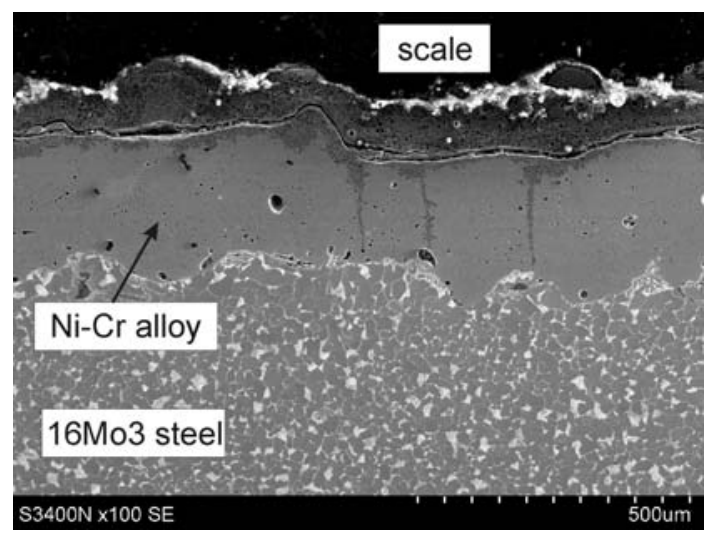

Fig. 4. Cross section of $\varnothing 57 \times 5.0 \mathrm{~mm}$ evaporator tube with thermal sprayed Ni-30Cr layer after one year exploitation

The layer of 50-100 $\mu \mathrm{m}$ in thickness consists of oxides and sulphides of chromium were formed on top of thermal sprayed coating. Other elements originated from combustion process were also detected in the scale (Tabl.2). The dense structure of coating prevents corrosion progress inside material. But it was revealed that coating 
were severely cracked (Fig.5b) - probably during exploitation, and this allow the corrosive species to attack the base material through the cracks. Cracks penetrated all the way through the coating. The ways of corrosive attack through the Ni-30Cr coating are visible in Fig. 4 and 5a. Sulphur presence was confirmed along the cracks and on the interface coating-base material.

a)

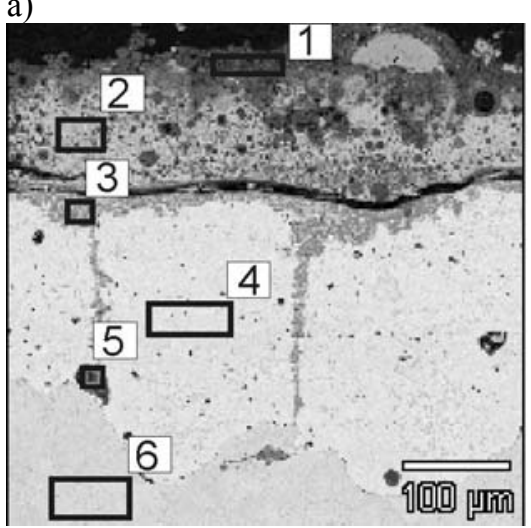

b)

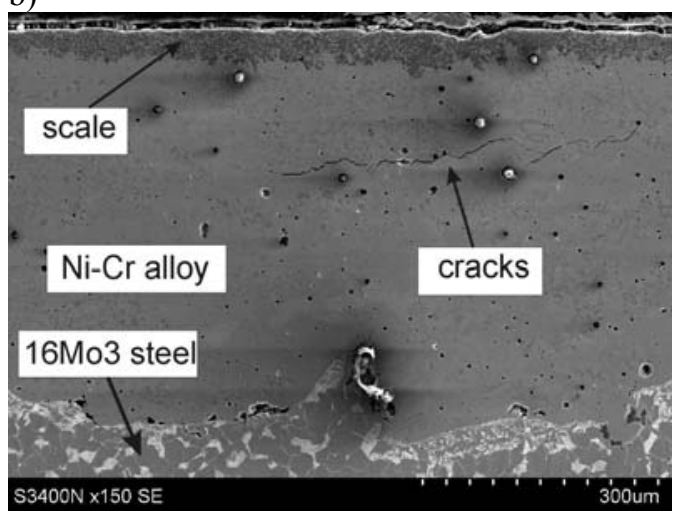

Fig. 5. Ni-30Cr coating after one year exploitation, a) places for chemical analysis (EDS), b) general view

Table 2. Chemical analysis at the points indicated in Fig. 5a (wt.\%)

\begin{tabular}{|l|l|l|l|l|l|l|l|l|l|l|}
\hline & $\mathrm{Na}$ & $\mathrm{Mg}$ & $\mathrm{Al}$ & $\mathrm{Si}$ & $\mathrm{S}$ & $\mathrm{K}$ & $\mathrm{Ca}$ & $\mathrm{Cr}$ & $\mathrm{Fe}$ & $\mathrm{Ni}$ \\
\hline pt1 & 1.71 & 1.24 & & 1.85 & 5.63 & 4.06 & 1.69 & 59.41 & 9,39 & 15.02 \\
\hline pt2 & & 0.58 & 3.64 & 2.44 & 12.28 & 0.23 & 0.62 & 62.89 & 3,99 & 13.33 \\
\hline pt3 & & & & 12.76 & 6.86 & & & 45.07 & 7.21 & 28.10 \\
\hline pt4 & & & & 5.12 & & & & 21.73 & 3.83 & 69.32 \\
\hline pt5 & & 2.21 & 3.63 & 3.31 & 2.60 & & & 13.15 & 38.77 & 36.33 \\
\hline pt6 & & & & & & & & & 98.89 & \\
\hline
\end{tabular}

Plasma thermal sprayed coating with double layer consists of Ni-30Cr alloy and ceramic $\mathrm{Al}_{2} \mathrm{O}_{3}$ layer is shown in Fig. 6 and 7. The total thickness of the coating reaches $650 \mu \mathrm{m}$. Inner $\mathrm{Ni}-30 \mathrm{Cr}$ layer of $250 \mu \mathrm{m}$ in thickness show the lamellar structure of particle splats with oxides at splat boundaries and voids (Fig. 7a). This layer is well adherent to the base material. Due to high energy of particles striking the tubes surface the steel grains were deformed and folded making good mechanical bonding between the base material and coating.

The thickness of outer $\mathrm{Al}_{2} \mathrm{O}_{3}$ layer exceeds $350 \mu \mathrm{m}$. This layer was rather porous, and contains many voids at splat boundaries. Inspection after one year operation in steam boiler indicated presence of many short cracks running perpendicularly to the surface with tendency to join into macrocracks. Many cracks situated parallel to the tube surface were detected near $\mathrm{Al}_{2} \mathrm{O}_{3} / \mathrm{Ni}-30 \mathrm{Cr}$ interface (Fig.7b)

Ceramic $\mathrm{Al}_{2} \mathrm{O}_{3}$ layer seems to be completely immune to corrosion attack in low emission combustion environment. The surface of coating was only locally covered with thin deposits of ashes. Although detailed investigations revealed that corrosive spices could reach base material through cracks and porosity of both layers. Spot chemical analysis of splat boundaries in inner Ni-30Cr layer indicated increased sulphur concentrations even at the base material interface (Fig. 7a, Table 3). 


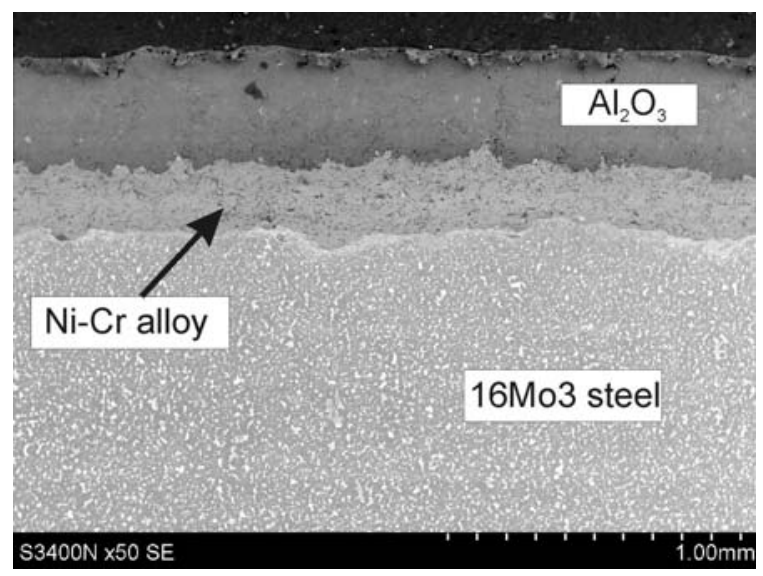

Fig. 6. Cross section of $\varnothing 57 \times 5.0 \mathrm{~mm}$ evaporator tube with double plasma sprayed layer after one year exploitation

a)

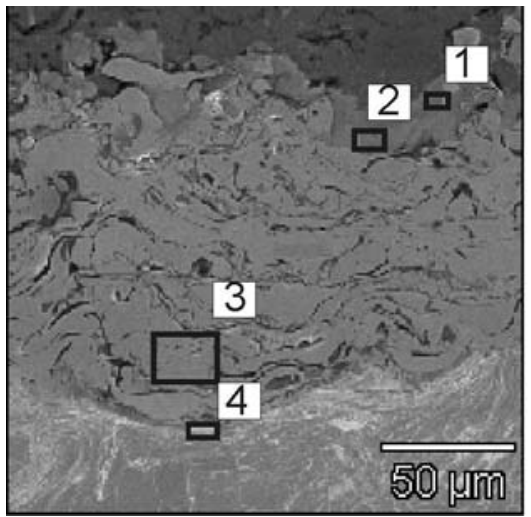

b)

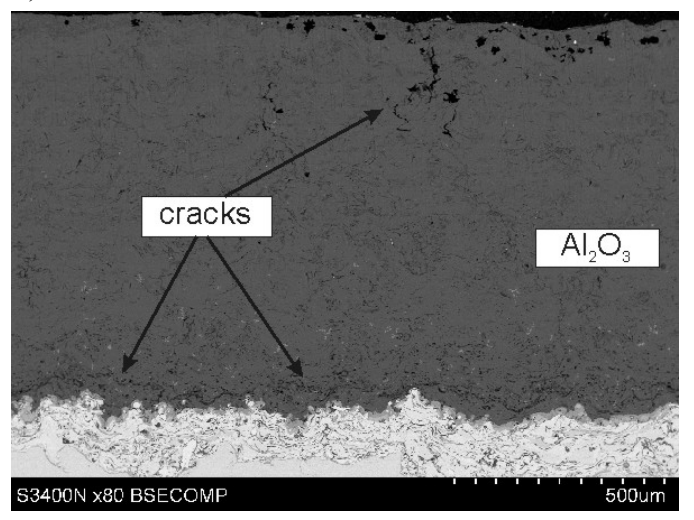

Fig. 7. Double, $\mathrm{Al}_{2} \mathrm{O}_{3} / \mathrm{Ni}-30 \mathrm{Cr}$ coating after one year operation, a) places for chemical analysis (EDS), b) general view

Table3. Chemical analysis at the points indicated in Fig. 7a (wt.\%)

\begin{tabular}{|l|c|c|c|c|c|c|c|}
\hline & $\mathrm{Al}$ & $\mathrm{Si}$ & $\mathrm{S}$ & $\mathrm{Cr}$ & $\mathrm{Mn}$ & $\mathrm{Fe}$ & $\mathrm{Ni}$ \\
\hline pt1 & 59.83 & 1.32 & & 8.36 & & 0.56 & 29.92 \\
\hline pt2 & 42.92 & 0.51 & & 7.86 & & 1.01 & 47.70 \\
\hline pt3 & 5.75 & 0.55 & & 17.41 & 0.62 & 1.25 & 74.41 \\
\hline pt4 & 1.19 & 0.33 & 1.69 & 1.81 & & 90.07 & 4.91 \\
\hline
\end{tabular}

Inspection after two years exploitation was performed only on tubes with double $\mathrm{Al}_{2} \mathrm{O}_{3} / \mathrm{Ni}-30 \mathrm{Cr}$ coatings. The huge degradation of protective coatings was recorded. Great areas of tubes surfaces were found without thermal sprayed layers at all. The only evidence of former coatings was the deformed layer of base material adjacent to Ni$30 \mathrm{Cr}$ layer. Corrosion products found on the base material consist only of iron oxides and sulfides.

Sulphides at coating-base material interface after one year operation attacked steel and cause disintegration of the coating (Fig. 8a,b). Firstly corrosion pits penetrated base material perpendicularly to the tube surface. Then corrosion process spread parallel to the surface causing separation of coatings and uncovers base material to combustion environment. 

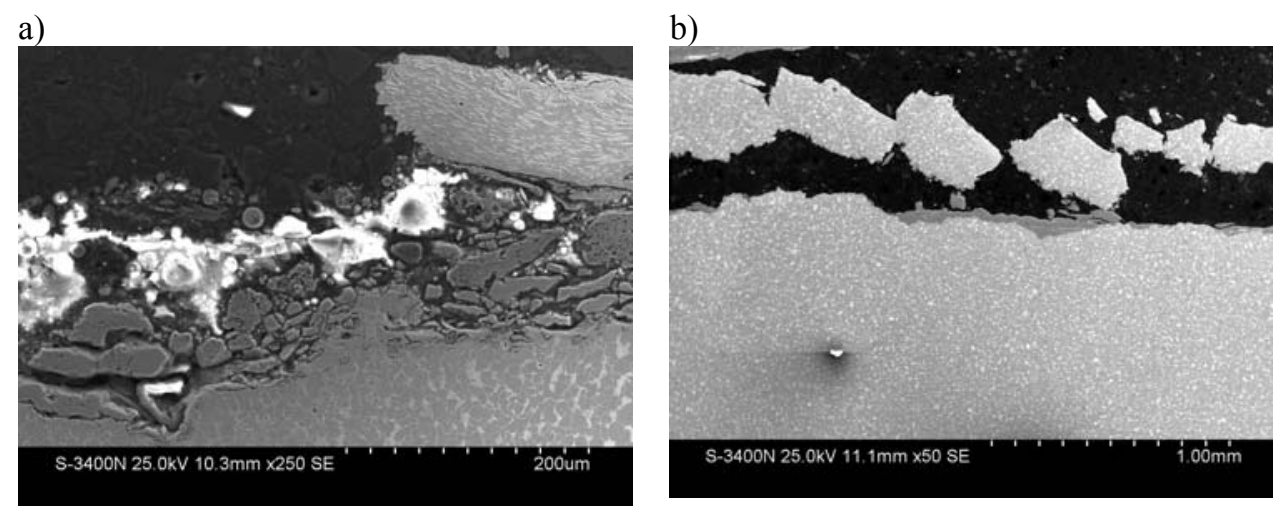

Fig. 8. Disintegration of the layer of base material of $\varnothing 57 \times 5.0 \mathrm{~mm}$ evaporator tube

\section{DISCUSSION}

Substiochiometric combustion conditions lead to sulfide and molten salt corrosion of water-wall tubes surfaces which cause considerable wall thickness reductions. The morfology of scales consisted of: external, porous and weakly connected layer and internal layer which was dense and adherent to the base metal. In both layers the high sulphur contents were detected as well as high amounts of alkaline metals.

Tubes with single Ni-30Cr arc sprayed surface layer were also susceptible to flue gases reducing environment. The corrosion resistance of $\mathrm{Ni}-\mathrm{Cr}$ coatings depend on their composition and increases with increasing chromium content [3,4]. Quality of nickel based coatings depends on their structure. Oxides at splat boundaries, cracks and voids can open the way for movement of chemical species and are a reason of corrosion damages. To enhance properties of Ni based coatings, heat treatment or laser melting processes are recommended.

Tubes with double layer $\mathrm{Al}_{2} \mathrm{O}_{3} / \mathrm{Ni}-30 \mathrm{Cr}$ coatings showed very good corrosion resistance. $\mathrm{Al}_{2} \mathrm{O}_{3}$ ceramic surface was almost immune to high temperature corrosion attack after one year service. Only traces of slag deposits were found on external surface of the tube. However this excellent corrosion resistance may be deteriorated by internal stresses producing cracks that were detected inside the layer. The amount of cracks inside the ceramic layer depends on its thicknesses and applied technology of thermal spraying. Examined coatings failed in the second year of service.

Usability of $\mathrm{Al}_{2} \mathrm{O}_{3}$ coatings on water-wall tubes in low $\mathrm{NO}_{\mathrm{x}}$ emission boilers is controversial. Very high corrosion resistance does not correspond with other requirements for good protective layers. Low heat conductivity of such layers, porosity and susceptibility to cracking restrict their applications.

\section{CONCLUSIONS}

1. Substiochiometric combustion conditions in low $\mathrm{NO}_{\mathrm{x}}$ emission boiler caused sulphide corrosion and molten salt corrosion of water-wall tubes surfaces. 
2. Tube's wall thickness reductions reach $68 \%$ of its nominal value after one year of exploitation.

3. Tubes with single Ni-30Cr arc sprayed surface layer were also susceptible to sulphide corrosion due to presence of internal voids and cracks.

4. Double $\mathrm{Al}_{2} \mathrm{O}_{3} / \mathrm{Ni}-30 \mathrm{Cr}$ coatings withstand corrosion attack for more than one year operation, then failed due to internal heterogenity and cracks generation that open the way for movement of chemical species toward the base material.

\section{REFERENCES}

1. G.Y. Lai, High-temperature corrosion of engineering alloys, ASM International, 1997.M.A.

2. J. Łabanowski, J. Ćwiek, S. Topolska, High temperature corrosion of evaporator tubes in low-emission steam boilers. Advances in Materials Science, Vol. 7, No.2(12) June 2007 27-31.

3. Uusitalo, P.M.J. Vursto, T.A. Mantyla, High temperature corrosion of coatings and boiler steels in reducing chlorine-containing atmosphere, Surface \&Coatings Technology 161 (2002) 275-285.

4. L. Xuefeng, Corrosion behaviours of two nickel base coatings in $\mathrm{H}_{2} \mathrm{~S}$ containing environments, Surface \&Coatings Technology 183 (2004) 212215.

5. K. Yamada et al., Hot corrosion behaviour of boiler tube materials in refuse incineration environment, Vaccum 65 (2002) 533-540. 